\title{
Effects of Acid Characteristics of Nanoporous MCM-48 on the Pyrolysis Product Distribution of Waste Pepper Stem
}

\author{
Young-Kwon Park, ${ }^{1,2}$ Myung Lang Yoo, ${ }^{3}$ and Sung Hoon Park ${ }^{3}$ \\ ${ }^{1}$ Graduate School of Energy and Environmental System Engineering, University of Seoul, Seoul 130-743, Republic of Korea \\ ${ }^{2}$ School of Environmental Engineering, University of Seoul, Seoul 130-743, Republic of Korea \\ ${ }^{3}$ Department of Environmental Engineering, Sunchon National University, Suncheon, Jeonnam 540-950, Republic of Korea
}

Correspondence should be addressed to Sung Hoon Park; shpark@sunchon.ac.kr

Received 25 July 2014; Accepted 7 August 2014; Published 19 August 2014

Academic Editor: Ki-Joon Jeon

Copyright (C) 2014 Young-Kwon Park et al. This is an open access article distributed under the Creative Commons Attribution License, which permits unrestricted use, distribution, and reproduction in any medium, provided the original work is properly cited.

\begin{abstract}
Nanoporous catalysts Si-MCM-48 and Al-MCM-48 were applied for the first time to the catalytic pyrolysis of waste pepper stem. Pyrolysis experiments were conducted at $550^{\circ} \mathrm{C}$ using Py-GC/MS to examine the product distribution rapidly. Phenolics were shown to be the most abundant product species of noncatalytic pyrolysis, whereas aliphatic and aromatic hydrocarbons were produced marginally. On the other hand, much larger quantities of furans and aliphatic and aromatic hydrocarbons were produced from the catalytic pyrolysis over MCM-48, while the production of phenolics was suppressed significantly. Al-MCM- 48 showed a much higher catalytic activity than Si-MCM-48, which was attributed to its much higher acidity. The results of this study indicate that valuable chemicals can be produced from waste pepper stem using catalytic pyrolysis over an acidic nanoporous catalyst.
\end{abstract}

\section{Introduction}

Bioenergy is one of the cheapest renewable energy sources at the state-of-the-art technology level. A variety of types of bioenergy, for example, biodiesel and bioethanol, are widely developed and used over the world accounting for about $15 \%$ of the current global energy use, while other renewable energy sources, such as solar energy, cannot compete with conventional fossil energy sources without considerable government subsidy. This is particularly true in South Korea. According to the plan of Korean government for the energy supply in 2030, bioenergy accounts for 30\% of total renewable energy supply, following waste energy (33.4\%) which is also mostly comprised of organic wastes [1]. Therefore, the effective recycling of waste biomass has a crucial implication in South Korea in terms of both renewable energy supply and waste reduction.

Another important advantage of using waste biomass as a bioenergy source is that it does not cause typical problems raised by energy crops: destruction of forest and reduction of food production [2]. Therefore, a significant attention has been paid to the development of technologies for effective use of organic wastes in energy production [3-5].

Red pepper is widely cultivated over Jeonnam Province of South Korea. The total production of red pepper in South Korea was approximately 1.2 million tons in 2009. Most waste pepper stems are burned or abandoned because it is difficult to compost them or use them as forage.

The thermochemical process in which biomass is heated under an oxygen-free condition to convert biomass to solid, liquid and gaseous fuels is called pyrolysis [6]. Among different pyrolysis techniques, fast pyrolysis refers to the pyrolysis process where residence time in reactor is very short and the temperature rising rate is high. Fast pyrolysis is known to be effective in maximizing the yield of the liquidphase pyrolysis product, called biooil [7].

Recently we reported the results of a noncatalytic pyrolysis experiment of waste red pepper stem [8]. The most abundant species in biooil obtained from the pyrolysis of waste pepper stem was phenolics, indicating that it might be possible to produce significant amount of aromatics (aromatic hydrocarbons) if catalytic reforming of the biooil 
is conducted over adequate catalysts $[4,9]$. This study was motivated by the necessity of evaluation of the potential of pepper stem for the production of valuable chemicals such as aromatics by means of catalytic pyrolysis.

Al-MCM-48 is a nanoporous catalyst which is known to be effective in converting large-molecular-mass organic materials to biooil due to its large pore size [10]. In particular, it is known to have high selectivity toward aromatics production [11]. In this study, the catalytic pyrolysis of waste pepper stem over Al-MCM-48 was carried out for the first time. SiMCM-48 was also used to investigate the effect of the acidity of the catalyst on the pyrolysis product distribution.

\section{Experimental}

Waste red pepper stems were collected in Jeonnam. The collected biomass was dried and processed into uniform size of $2 \mathrm{~mm}$ diameter. The sample particles were then dried further in an oven controlled at $105^{\circ} \mathrm{C}$ for $24 \mathrm{~h}$. It was reported in a previous study that the waste red pepper stem is composed of $46.4 \% \mathrm{O}, 46.2 \% \mathrm{C}, 5.6 \% \mathrm{H}$, and $1.8 \% \mathrm{~N}$ in terms of elemental analysis and of $2.8 \%$ moisture, $68.1 \%$ volatile matter, $23.3 \%$ fixed carbon, and $5.8 \%$ ash in terms of proximate analysis.

Si-MCM-48 and Al-MCM-48 were prepared following the method suggested previously $[12,13]$. After their synthesis, the catalysts were calcined at $550^{\circ} \mathrm{C}$ for $3 \mathrm{~h}$. Before each experiment, all the catalysts were dried in a $110^{\circ} \mathrm{C}$ oven for at least 2 hours.

The characteristics of the catalysts used in this study were examined in a previous study [14]. Nitrogen sorption analysis, X-ray diffraction (XRD), temperature programmed desorption of ammonia ( $\left.\mathrm{NH}_{3}-\mathrm{TPD}\right)$, and pyridine FT-IR were used. The acidity of the catalysts was determined by $\mathrm{NH}_{3}$-TPD analysis. The nature of the acid sites was examined using pyridine as the probe molecule. The surface area, pore volume, and pore size of Si-MCM-48 were $1036 \mathrm{~m}^{2} / \mathrm{g}$, $0.85 \mathrm{~cm}^{3} / \mathrm{g}$, and $2.9 \mathrm{~nm}$, respectively, whereas those of AlMCM-48 were $864 \mathrm{~m}^{2} / \mathrm{g}, 0.81 \mathrm{~cm}^{3} / \mathrm{g}$, and $2.9 \mathrm{~nm}$, respectively. The Si/Al ratio of Al-MCM-48 was 40. Al-MCM-48 was shown to have significant amount of Lewis acid sites, whereas Si-MCM-48 had few acid sites.

Pyrolysis experiments were performed using pyrolysisgas chromatography/mass spectrometry (Py-GC/MS), which is a combination of GC (HP $6890 \mathrm{~N}$ Gas Chromatography)/MS (HP 5973 inert Mass Spectral Detector, Agilent Technologies Inc., Santa Clara, CA, USA) and a vertical furnace-type pyrolyzer (Py-2020D, Frontier-Lab Ltd., Fukushima, Japan), to analyze the pyrolysis product directly. A sample cup containing well-mixed biomass-catalyst mixture of $1 \mathrm{mg}$ of pepper stem and $1 \mathrm{mg}$ of catalyst was inserted into the pyrolyzer preheated to $550^{\circ} \mathrm{C}$. As the carrier gas that flows through the pyrolyzer, helium gas with the split ratio of $50: 1$ was used. The pyrolysis reaction was allowed to take place for $3 \mathrm{~min}$. The analysis of the species distribution of the vapor-phase pyrolysis product was performed using $\mathrm{GC} / \mathrm{MS}$, whose interface temperature was $300^{\circ} \mathrm{C}$. The GC oven temperature was increased from $40^{\circ} \mathrm{C}$ to $300^{\circ} \mathrm{C}$ at a rate of $5^{\circ} \mathrm{C} / \mathrm{min}$. Before and after the temperature rising, temperature was maintained at $40^{\circ} \mathrm{C}$ for $4 \mathrm{~min}$ and at $300^{\circ} \mathrm{C}$ for $10 \mathrm{~min}$, respectively. An HP-5 MS $(30 \mathrm{~m} \times 0.25 \mathrm{~mm} \times$ $0.25 \mathrm{~m}$ ) capillary column was used for GC/MS. The peaks appearing in the mass spectra were interpreted using the NIST05 library.

\section{Results and Discussion}

For effective examination of the impacts of the catalyst on the pyrolysis product composition, all the species detected by GC/MS were divided into 8 categories: gas, acids, oxygenates, phenolics, aliphatics (aliphatic hydrocarbons), aromatics, PAHs, and $\mathrm{N}$ compounds. Figure 1 compares the product distributions, in terms of the area\%, obtained from different catalysis conditions. When the pepper stem was pyrolyzed without catalyst, phenolics were the most abundant products, followed by oxygenates and acids. The production of aliphatics and aromatics was insignificant. When the pyrolysis was performed over MCM-48 catalysts, however, the fraction of phenolics decreased dramatically. On the other hand, the production of all other products, including aliphatics and aromatics, was enhanced. This catalytic effect was more profound for more acidic catalyst, Al-MCM-48. For deeper understanding, the detailed species distributions of oxygenates, phenolics, and aromatics were investigated.

Figure 2 compares the detailed species distributions of oxygenates obtained from different catalysis conditions. It is shown in this figure that levoglucosan, which accounted for a significant fraction in the noncatalytic pyrolysis product, disappeared completely in the catalytic pyrolysis products. On the other hand, the fraction of furans increased dramatically. Because furans are high-value-added products used as organic solvents for the production of medicines, resins, and food and fuel additives, the enhanced production of furans is beneficial $[15,16]$. Furans are known to be produced when carbohydrates, such as levoglucosan, are dehydrated over an acidic catalyst [15]. If the acidity of the catalyst is strong enough, furans may be converted further to aromatics $[17,18]$, which was witnessed in the present study as well when Al-MCM-48, with a higher acidity, led to a more enhanced production of aromatics than that of Si-MCM-48 (Figure 1).

Phenolics were the most dominant product species from the noncatalytic pyrolysis of pepper stem because of the high lignin content of pepper stem (32\% according to Won and $\mathrm{Oh}$ [19]) but the catalytic reforming reduced the fraction of phenolics to a large extent (see Figure 1). Figure 3 shows the species distribution of phenolics produced under different catalysis conditions. It is shown that the fractions of heavy phenolics mostly decreased as a result of catalytic reforming, while those of light phenols, such as phenol and methyl phenols, rather increased, particularly when Al-MCM-48 was used. The reduction of the heavy phenolic fraction was more significant when Al-MCM-48 was used because of its higher acidity. This can be attributed to the cracking of heavy phenols, produced by the decomposition of lignin, into light phenols and other species, such as aromatics, in the presence of a catalyst with high acidity. Based on their experimental results on the catalytic pyrolysis of Laminaria japonica over Al-MCM-48, Lee et al. [11] argued that phenolics were 


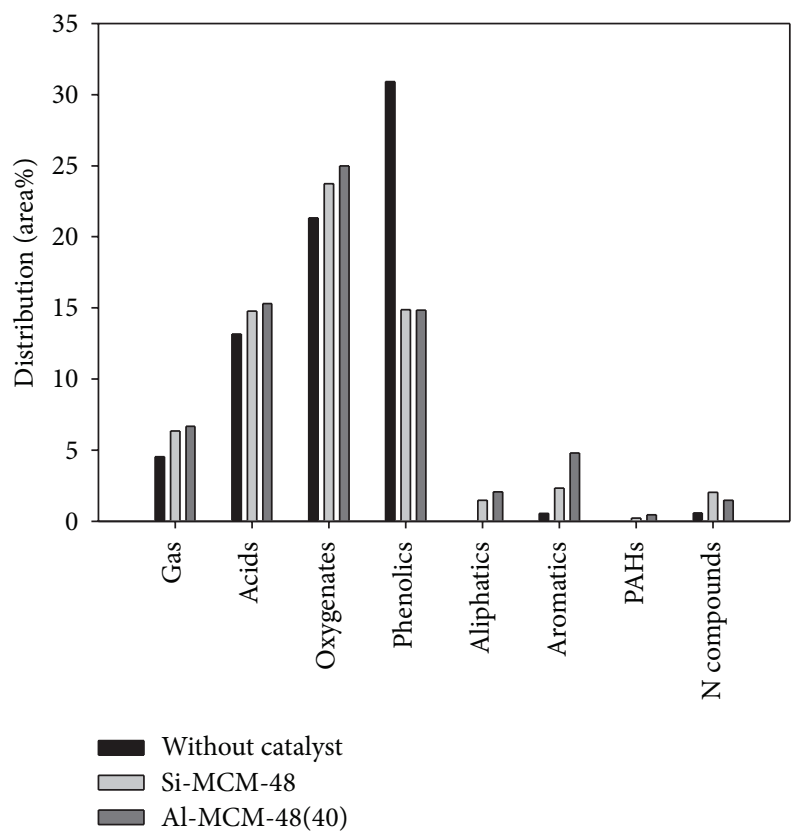

FIGURE 1: Pyrolysis product distribution obtained under different catalysis conditions.

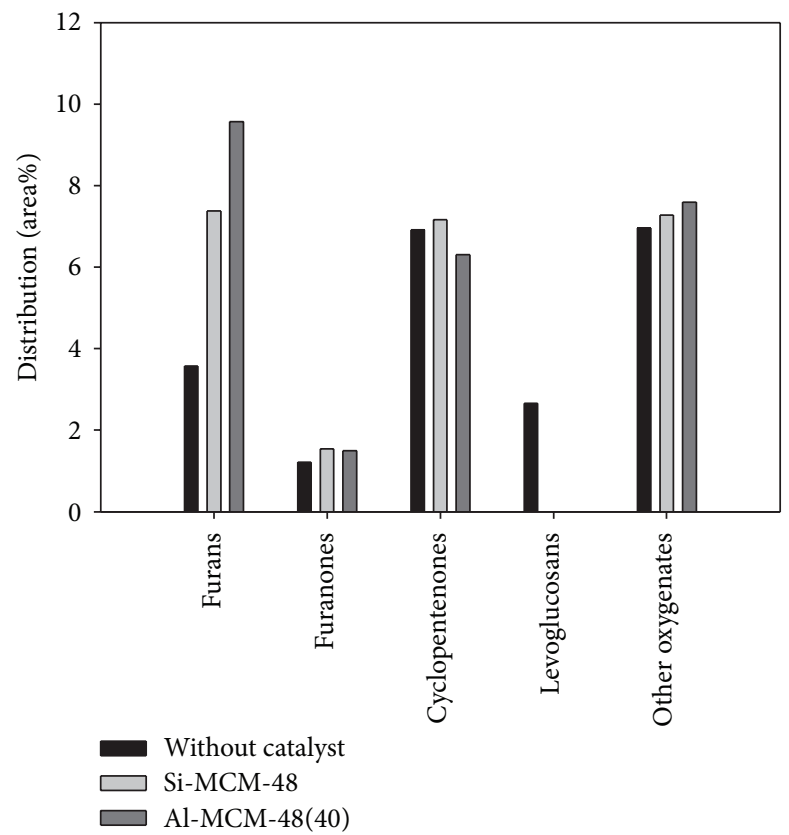

FIgURE 2: Detailed species distribution of oxygenates obtained under different catalysis conditions.

converted into aromatics on the acid sites of Al-MCM-48, which is in agreement with the result of the present study.

Figure 4 compares the fractions of BTEX species (benzene, toluene, ethylbenzene, and xylene), the most important aromatic compounds, produced under different catalysis conditions. Because these compounds can be used as feedstock materials in petrochemical processes, their fraction in biooil is an important factor determining the valueadded of the oil. The production of aromatics is a result of complicated reaction pathways including cracking, dehydrogenation, oligomerization, and aromatization, which require strong acid sites on the catalyst $[4,9]$. The production of BTEX was negligible in the case of noncatalytic pyrolysis, whereas it was considerably enhanced when the product oil was reformed over MCM-48 catalysts. In particular, the catalytic effect was much stronger for Al-MCM-48 because of its much higher acidity than that of Si-MCM48. 


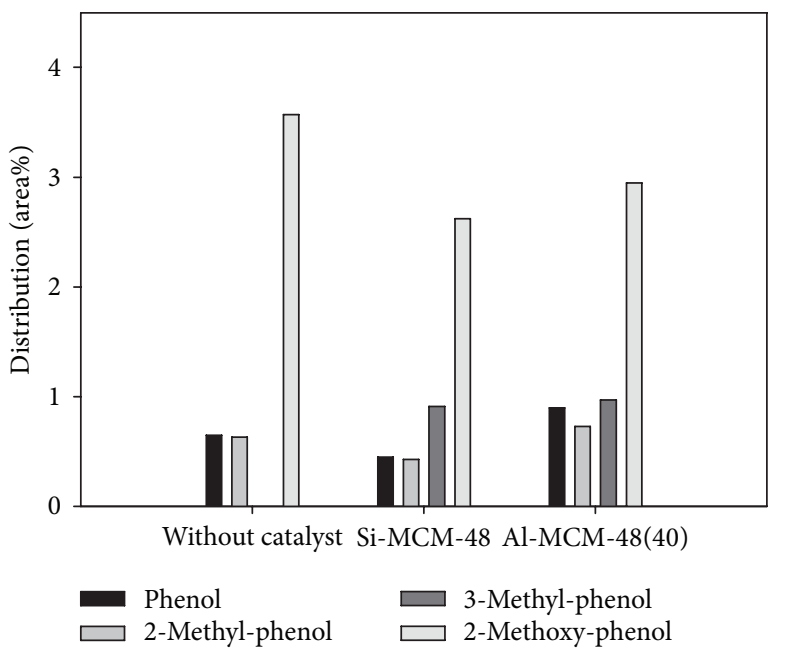

(a)

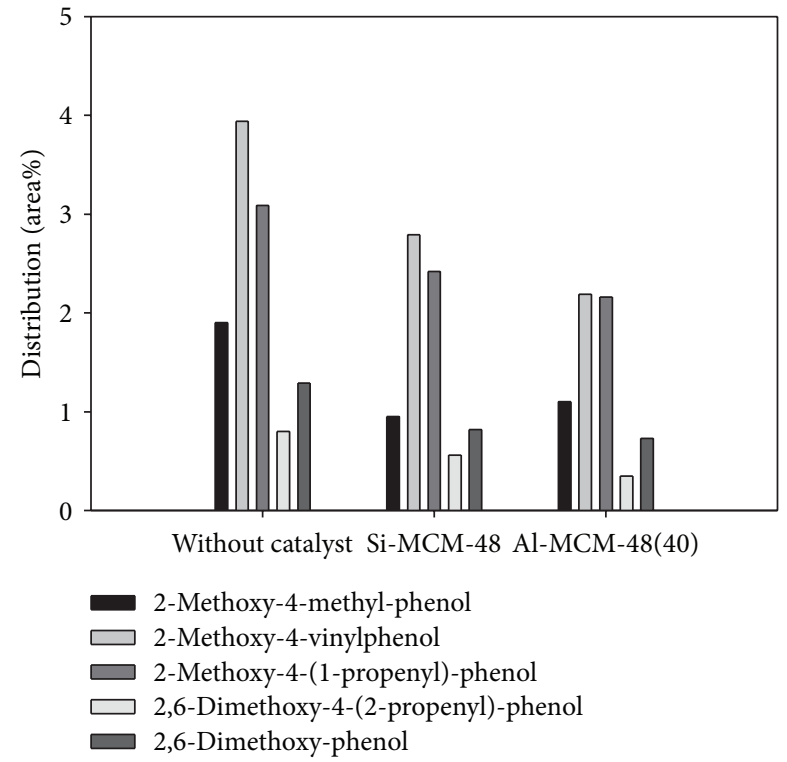

(b)

FIGURE 3: Detailed species distribution of phenolics obtained under different catalysis conditions: (a) small-molecular-mass phenolics; (b) large-molecular-mass phenolics.

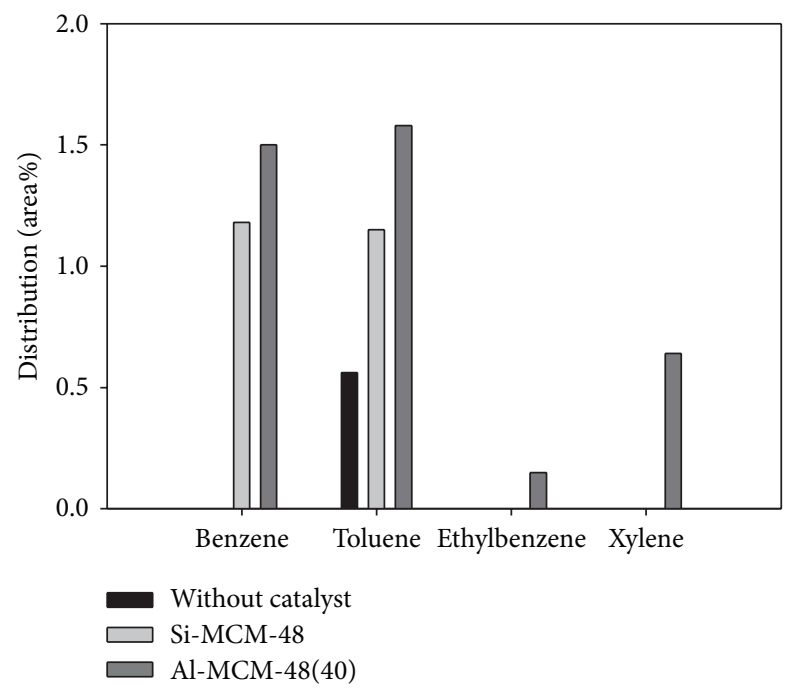

FIgURE 4: Comparison of the BTEX fractions obtained under different catalysis conditions.

\section{Conclusions}

Phenolics were the most dominant product species of the noncatalytic pyrolysis of waste pepper stem, while the production of aliphatic and aromatic hydrocarbons was insignificant. When the pyrolysis was conducted over MCM-48 catalysts, however, the production of furans and aliphatic and aromatic hydrocarbons was enhanced considerably, whereas the fraction of phenolics decreased significantly. This catalytic effect was more profound for Al-MCM-48, due to its higher acidity, than for Si-MCM-48. This study suggests that the catalytic pyrolysis over an acidic nanoporous catalyst can be a reasonable way of producing valuable chemicals from waste pepper stem.

\section{Conflict of Interests}

The authors declare that there is no conflict of interests regarding the publication of this paper.

\section{Acknowledgments}

This research was supported by Basic Science Research Program through the National Research Foundation of Korea (NRF) funded by the Ministry of Education (Grant number 2013R1A1A4A01005840). This paper was also supported in part by Sunchon National University Research Fund in 2013.

\section{References}

[1] Ministry of Environment Republic of Korea, Low Carbon Green Growth, 2009, (Korean).

[2] M. Z. Jacobson, "Review of solutions to global warming, air pollution, and energy security," Energy and Environmental Science, vol. 2, no. 2, pp. 148-173, 2009.

[3] L. Helsen, E. van den Bulck, and J. S. Hery, "Total recycling of CCA treated wood waste by low-temperature pyrolysis," Waste Management, vol. 18, no. 6-8, pp. 571-578, 1998.

[4] H. J. Park, H. S. Heo, J. K. Jeon et al., "Highly valuable chemicals production from catalytic upgrading of radiata pine sawdust-derived pyrolytic vapors over mesoporous MFI zeolites," Applied Catalysis B: Environmental, vol. 95, no. 3-4, pp. 365-373, 2010. 
[5] A. N. Phan, C. Ryu, V. N. Sharifi, and J. Swithenbank, "Characterisation of slow pyrolysis products from segregated wastes for energy production," Journal of Analytical and Applied Pyrolysis, vol. 81, no. 1, pp. 65-71, 2008.

[6] D. Mohan, C. U. Pittman Jr., and P. H. Steele, "Pyrolysis of wood/biomass for bio-oil: a critical review," Energy and Fuels, vol. 20, no. 3, pp. 848-889, 2006.

[7] A. Demirbas, "Biomass resources for energy and chemical industry," Energy Education, Science and Technology, vol. 5, pp. 21-45, 2000.

[8] Y.-K. Park, M. L. Yoo, H. W. Lee, S. H. Park, S.-C. Jung, and S.-C. Kim, "Effects of operation conditions on pyrolysis characteristics of agricultural residues," Renewable Energy, vol. 42, pp. 125-130, 2012.

[9] H. S. Heo, S. G. Kim, K. E. Jeong et al., "Catalytic upgrading of oil fractions separated from food waste leachate," Bioresource Technology, vol. 102, no. 4, pp. 3952-3957, 2011.

[10] H. J. Park, K. H. Park, J. K. Jeon et al., "Production of phenolics and aromatics by pyrolysis of miscanthus," Fuel, vol. 97, pp. 379384, 2012.

[11] H. W. Lee, J. K. Jeon, S. H. Park, K. E. Jeong, H. J. Chae, and Y. K. Park, "Catalytic pyrolysis of Laminaria japonica over nanoporous catalysts using Py-GC/MS," Nanoscale Research Letters, vol. 6, article 500, 2011.

[12] H. J. Park, J. H. Yim, J. K. Jeon, J. M. Kim, K. S. Yoo, and Y. K. Park, "Pyrolysis of polypropylene over mesoporous MCM-48 material," Journal of Physics and Chemistry of Solids, vol. 69, no. 5-6, pp. 1125-1128, 2008.

[13] S. H. Lee, H. S. Heo, K. E. Jeong et al., "Catalytic pyrolysis of oilsand bitumen over nanoporous catalysts," Journal of Nanoscience and Nanotechnology, vol.11, no. 1, pp. 759-762, 2011.

[14] H. W. Lee, I. G. Lee, S. H. Park et al., "Application of mesoporous Al-MCM-48 material to the conversion of lignin," Journal of Nanoscience and Nanotechnology, vol. 14, no. 4, pp. 2990-2995, 2014.

[15] M. J. Jeon, J. K. Jeon, D. J. Suh et al., "Catalytic pyrolysis of biomass components over mesoporous catalysts using PyGC/MS," Catalysis Today, vol. 204, pp. 170-178, 2013.

[16] Q. Lu, W. M. Xiong, W. Z. Li, Q. X. Guo, and X. F. Zhu, "Catalytic pyrolysis of cellulose with sulfated metal oxides: a promising method for obtaining high yield of light furan compounds," Bioresource Technology, vol. 100, pp. 4871-4876, 2009.

[17] Y. T. Cheng and G. W. Huber, "Chemistry of furan conversion into aromatics and olefins over HZSM-5: a model biomass conversion reaction," ACS Catalysis, vol. 1, pp. 611-628, 2011.

[18] Y. K. Park, B. R. Jeon, S. H. Park et al., "Catalytic conversion of cellulose over mesoporous Y zeolite," Journal of Nanoscience and Nanotechnology, vol. 14, no. 7, pp. 5120-5123, 2014.

[19] K.-Y. Won and K.-K. Oh, "Optimization the xylose fractionation conditions of pepper stem with dilute sulfuric acid," $K S B B$ Journal, vol. 24, pp. 361-366, 2009. 

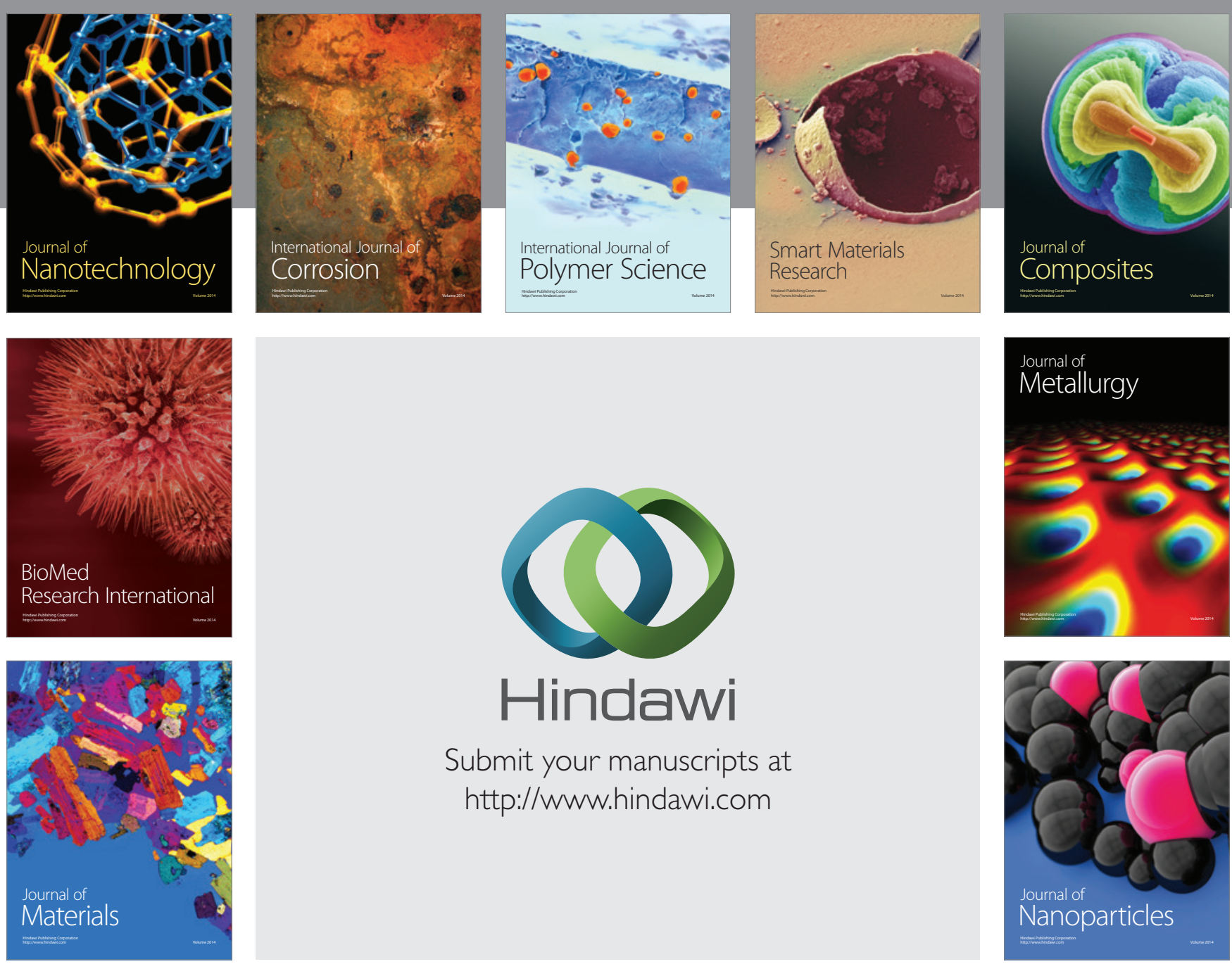

Submit your manuscripts at http://www.hindawi.com
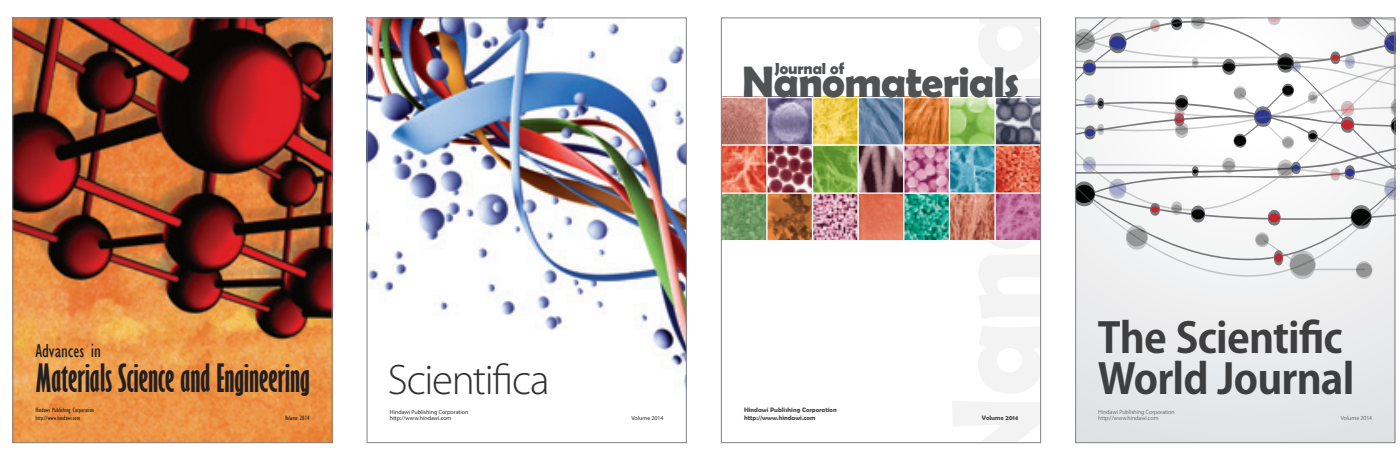

\section{The Scientific World Journal}
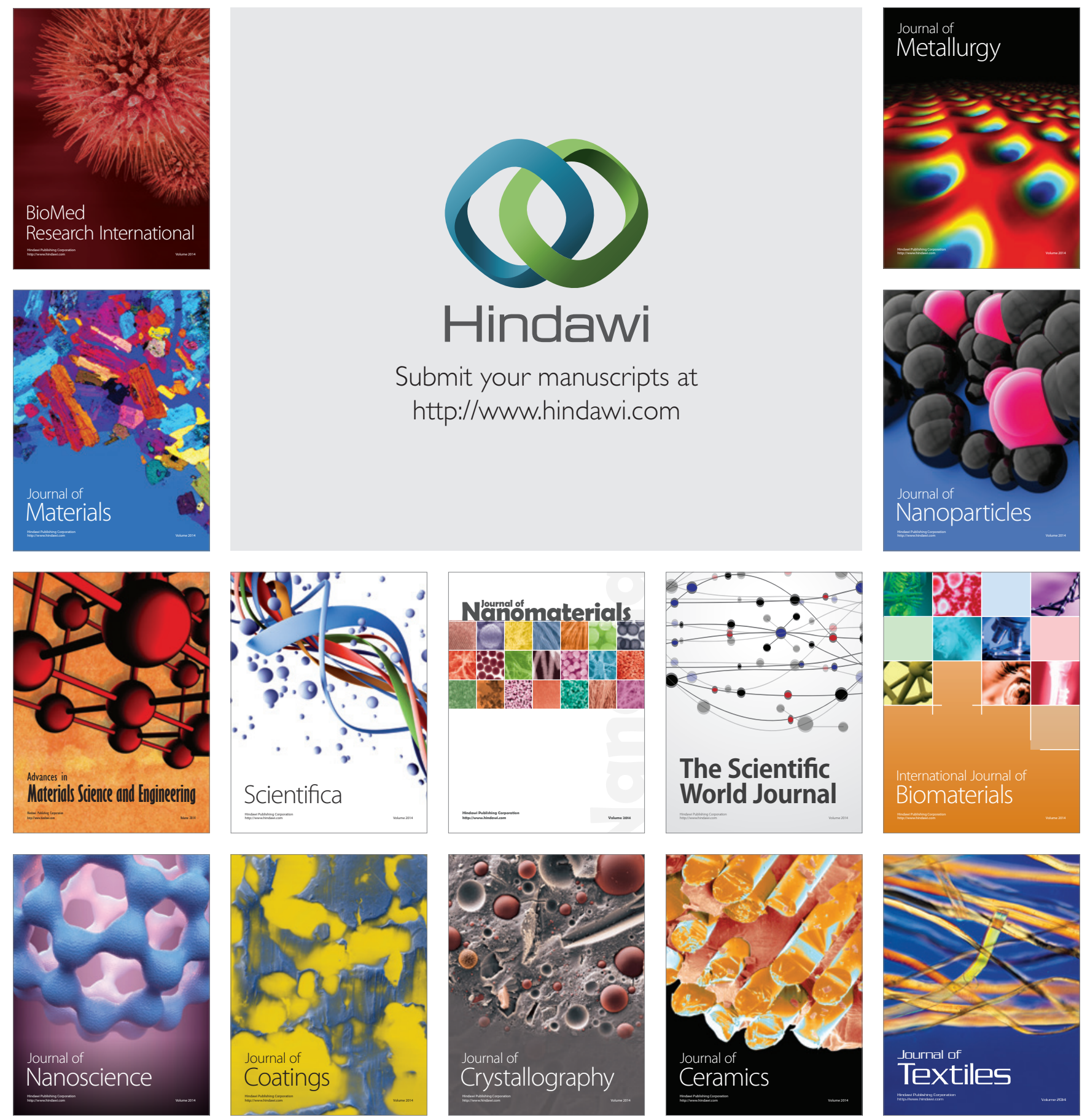